\title{
DETAILS OF ACTIVITIES DONE BY RECENTLY DELIVERED WOMEN FOR THEIR LAST DELIVERY IN UTTAR PRADESH, INDIA
}

\author{
DR. TRIDIBESH TRIPATHY*., DR. UMAKANT PRUSTY ${ }^{1}$ \& DR. CHINTAMANI NAYAK² \\ *BHMS (Utkal University, Bhubaneswar), MD(BFUHS,Faridkot), MHA (TISS, Mumbai), Ph.D. in Health Systems Studies (TISS, \\ Mumbai)Homoeopathic \& Public Health Expert, Subject Expert, Master of Public Health (Community Medicine) Course, Lucknow \\ University, Lucknow. \\ 'Research officer (Homoeopathy), Regional Research Institute (Homoeopathy), Puri, Odisha under Central Council for Research in \\ Homoeopathy, Ministry of AYUSH, Government of India. \\ ${ }^{2}$ Assistant Professor, National Institute of Homoeopathy, Kolkata, West Bengal, Government of India.
}

(Received on Date: 24th April 2020 Date of Acceptance: 20 20 th May 2020 Date of Publish: $01^{\text {st }}$ July 2020 )

Email id: tridibeshtripathy@gmail.com

\section{ABSTRACT}

Besides the Angan Wadi Workers that are in place since the early eighties, the current lot of CHWs in UP are the ASHAs who are the daughters-in-law of a family that resides in the same community that they serve as the grassroots health worker since 2005 when the NRHM was introduced in the EAG states. UP is one such Empowered Action Group (EAG) state. The current study explores the actual activities done by RDWs on birth preparedness, delivery attendants and place of delivery. Regarding the place, the article also deals with the decision maker at the household level. Following that, reasons are elicited from the RDWs for not opting for an institutional delivery. From the catchment area of each ASHA, two RDWs were selected who had a child in the age group of 3 to 6 months during the survey. The activity profiles of the RDWs on these aspects of delivery are reflected upon to give a picture that represents the entire state of UP.

The relevance of the study assumes significance as data on the modalities of actual actions done by the RDWs for their last delivery are not available even in large scale surveys like National Family Health Survey 4 done in 2015-16. The current study gives an insight in to these activities separately. The current study is basically regarding the repertory of the actions taken by RDWs during their stages of both pre and post pregnancies.

When late or poor decisions/actions are taken by the RDWs and their family members, it shows up poorly in the Infant Mortality Rates (IMR) and Maternal Mortality Ratios (MMR) in India and especially in UP. The current IMR in India is 33 where as it is 41 in UP which means 8 points higher per 1000 livebirths (SRS, May 2019). Similarly, the current MMR in India is 122 where as it is 216 in UP which really reflects poorly for UP in comparison to the data at 
national level (SRS, November, 2019). These mortalities are the impact indicators and such indicators can be reduced through long drawn processes that includes effective and timely actions by RDWs for their pregnancies \& deliveries. This is the area of activity detailing that the current study throws out.

A total of four districts of Uttar Pradesh were selected purposively for the study and the data collection was conducted in the villages of the respective districts with the help of a pre-tested structured interview schedule with both close-ended and open-ended questions. In addition, in-depth interviews were also conducted amongst the RDWs and a total 500 respondents had participated in the study.

The results showed that more than $95 \%$ of RDWs identified the place of delivery during pregnancy in all the 4 districts. Similarly, across all the 4 districts, more than $94 \%$ of RDWs had identified the vehicle for transport if there was a need. Regarding the act of saving money, it was seen that in three districts the RDWs had acted after receiving the messages from ASHAs. Only in Gonda district, 95\% RDWs had said that they knew about saving money but only $73 \%$ acted. Most of the deliveries in the four districts were conducted by the ANMs.

The data on type of deliveries showed that across the 4 districts most of the deliveries of the RDWs were normal deliveries. Across the four districts, it was found that contrary to the popular belief it was not the mother-in-law but the husbands and the father-in-law who took the decision regarding the place of delivery. Similarly, the data on the place of delivery showed that most of the deliveries were conducted in the CHCs. Further it was found that decision making by husbands at household was the prime reason for not conducting the delivery at health facility there by preferring for a home delivery.

Key words : RDW, ASHA, birth preparedness, CHW, Natal, Postnatal 


\section{INTRODUCTION}

As RDWs were selected from the catchment area of the ASHAs in the four districts, the following section briefs out the details on ASHAs.

The ASHAs were recruited by the Local Self Governance from their own communities as per the guidelines set by NHM. Subsequent to the roll out of guidelines at the central level, the state of UP also rolled out the recruitment of ASHAs through the setting up of State Program Management Unit of NHM at state level and the District Program Management Unit (DPMU) at district level. These DPMUs helped set up the Block Program Management Unit at the block level. These units got in touch with the Panchayati Raj Institutions which was part of LSGs and these PRIs represented by the Gram Pradhans or the village panchayat head nominated the ASHAs from the respective communities. They attached the ASHAs with the public health system at the block level to work as ASHAs who are incentive based workers. (GOUP, PIP, NHM, 2008).

Like India, UP also went through the $\mathrm{CHW}$ scheme in 1970s through the introduction of Village Health Guide in 1977 (5 $5^{\text {th }}$ Plan GOI, 1974-79) and the concept was ratified further in the Alma Ata conference of 1978 on primary health care. On the other hand, with the introduction of Integrated Child Development Services in 1975 (5th Plan GOI, 1974-79) the Angan Wadi Workers were in place as CHWs in phases. Simultaneously, local Traditional Birth Attendants were in place since 1977 as CHWs (5th plan, GOI, 1974-79). Thereafter, the multipurpose male and female health workers came in to place through the Child survival and Safe Motherhood program in 1992 (Yearly Plan, GOI, 1992). Besides the sporadic efforts of NGOs putting in place CHWs through their small efforts in definite geographic areas, the cadre of Basic Health Workers were put in by the health system from 1992 till 2005 (GOI, 2005). Gradually the CHWs came here to stay with the introduction of ASHAs in 2005 through the introduction of NRHM (GOI, 2005). As per GOUP, there were 1,50,000 ASHAs in UP in 2019. The selection of RDWs in this study is dependent on the ASHAs.

Studies on RDWs in UP have not covered on aspects like activities related to birth preparedness during pregnancy by the RDWs. Further details like decision maker in the family to decide the place of delivery and reasons for not going to an institution in case of home deliveries are not mentioned in detail in many large-scale surveys. The current study reflects on these aspects in detail including the actual activities done by the RDWs.

\section{Pre \& post Delivery activities for and of RDWs in UP}

The ASHAs emerged in India's public health system during the launch of NRHM in 2005 in the state of Uttar Pradesh (GOI, 2005). The ASHAs were in fact inducted to NRHM with the primary aim to roll out the JSY component of NRHM (GOI, 2005).

A study done in UP regarding the performance of ASHA mentions that the average percentage of home deliveries attended by each ASHA in UP is $32 \%$. It also mentions that all the ASHAs counseled the women on birth preparedness in UP. The 
activities performed by ASHAs with the RDWs are linked to their capacity building initiatives. Regarding these initiatives, the study mentions that $56.03 \%$ of ASHAs in UP think that the topic of pregnancy, child birth and Post Natal Care was optimally covered through theoretical training. Regarding practical training on these same issues, the study mentions that $62.93 \%$ of ASHAs think that these were covered optimally. (Bajpai N, Dholakia R, 2011). It is significant to note that here the ASHAs were the source of information as the eligible women were not the respondents unlike the current article.

The evaluation study of ASHA scheme by NRHM in UP states that $84.42 \%$ of eligible women reported that ASHA counseled them for birth preparedness \& $43.66 \%$ reported to be counseled on complications before delivery. $44.6 \%$ of Eligible Women (EW) reported that they planned for the transport in advance. Further, $9.54 \%$ of EW told that ASHA helped them in transport to the hospital. Regarding consideration of place, $64.4 \%$ of EW had considered their delivery in a Government hospital \& 9.4\% had in private. Home deliveries were considered by $26.2 \%$ of EW. The percentage of actual deliveries as per place shows that $50.1 \%$ had in Government hospital, $16.5 \%$ in private hospital and $33.4 \%$ in homes. The study also says that $84.9 \%$ of EW reported that family members or relatives accompanied them to hospital for delivery (GOUP,2013). Here again, we can see that indicators like decision maker for deliveries and reasons for not opting an institutional delivery is not mentioned.
The National Family Health Survey report written in 2017 for UP states that $68 \%$ of deliveries were institutional \& $32 \%$ were home deliveries. Among the home deliveries, $98 \%$ had used a clean blade whereas $33 \%$ of these deliveries used a Disposable Delivery Kit (DDK). Regarding births, $77 \%$ of the births were done by skilled provider, $16 \%$ by Traditional Birth Attendant (TBA) and $12 \%$ by friends or relatives. Regarding type of birth, $9 \%$ had caesarean section births out of which $55 \%$ of these births were emergency cases (NFHS 4, 2015 16).

The evaluation of Comprehensive Child Survival Program of UP done in 2013 states that $97.9 \%$ of women received counseling regarding birth preparedness. Further analysis shows that $68.7 \%$ of these women received counseling on transport, $91.8 \%$ on saving adequate money and $74.8 \%$ for the plan to take a person to accompany for the delivery. On the issue of preference of the place of delivery, $53.76 \%$ were for the Government hospital \& $46.24 \%$ for private hospital. Regarding the activities done by the ASHAs, it mentions that $74.9 \%$ of $\mathrm{EW}$ received information on birth preparedness by ASHAs and $75.9 \%$ of EW reported that ASHA helped them to make a birth plan (GOUP, CCSP, 2013).

The aspect of birth preparedness plan during pregnancy, place of delivery and the decision maker at home to decide the place of delivery is embedded in another study in UP. That study revealed that contacts with health worker during pregnancy, marginalization, at least three ANC visits \& institutional delivery were the strong determinants for utilization of Post 
Natal Services (Singh, R, et.al, 2019). In the current study, most of the RDWs replied on the actual activities they did on their recent delivery.

The current study done in 2017 is unique in the sense that it examines the profile of RDWs and their families in the catchment area of ASHAs regarding birth preparedness during pregnancy. The study also delves into the personnel, place, decision maker in the family regarding their delivery. It also elicits the reasons ascribed by the RDWs for not going to a health facility if the delivery is a home delivery.

\section{Research Methodology}

Using purposive sampling technique, four districts were chosen from the four different economic regions of UP, namely Central, Eastern, Western and Bundelkhand. Further, the Government of UP in 2009 categorized the districts as per their development status using a composition of 36 indicators. Purposefully, the high developed district chosen for the study is Saharanpur from the western region, the medium developed district chosen for the study is Barabanki from the central region, the low developed district chosen for the study is Gonda from the eastern region and the very low developed district chosen for the study is Banda from the Bundelkhand region (GOUP, 2009).

In the next step, purposefully two blocks were selected from each of the district and all the ASHAs in these blocks were chosen as the universe for the study. From the list of all the ASHAs in each of the two blocks, 31 ASHAs were chosen randomly from each block for the study. In this way, 62 ASHAs were chosen for the study from each of the districts. In Gonda district, 64 ASHAs were selected to make the total number of ASHAs for the study to 250. From the catchment area of each ASHA, two Recently Delivered Women (RDW) were chosen who had a child in the age group of 3-6 months during the time of the data collection for the study. In this way, 124 RDWs from three districts and 128 RDWs from Gonda district were chosen thus a total of 500 RDWs were selected for the study.

The following figure shows the four districts of UP in the map of the state of UP.

\section{Figure 1}

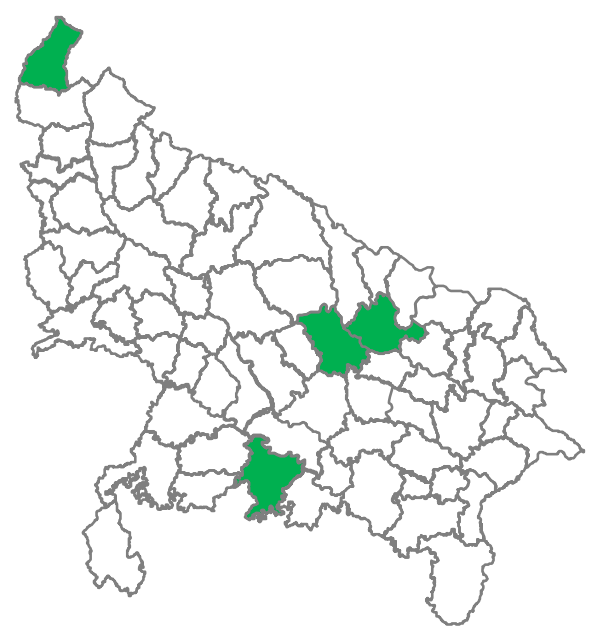


The data was analyzed using SPSS software to calculate the percentage and absolute values of the activities of and for RDWs using the detail profiles of the birth preparedness and perinatal care as per the data in the four study districts. The quantitative data related to the profiles was seen for \& of RDWs that forms the basis of the ensuing results and discussion.

\section{Research tools}

The RDWs were interviewed using an indepth, open-ended interview schedule which included a section on various components of birth preparedness and other modalities on delivery. The first table is from the section three of the tool that comes under the stage before delivery. The third section is on the ANC services and three questions are from this section. Thereafter, all other tables are related to section 4 of the tool that deals with natal and postnatal care. They were asked about the personnel who conducted the delivery, type of delivery, the decision maker in the family about the place of delivery, the actual place of delivery and finally about the reasons for not going to a health facility if the delivery was a home delivery. Five hundred research tools were used for the study to interview 500 recently delivered women who had a child in the age group of 3 to 6 months during the survey. The following section details out the results and discussions related to the study.

\section{Results and discussions}

There are 6 tables in this section. The first table is on birth preparedness activities when they were pregnant. The other 5 tables are on the activities they did regarding natal care. Besides these, there is one figure in the article that shows the districts through an outline map of UP.

\section{Table 1- Identification of place of delivery during pregnancy.}

\begin{tabular}{|l|l|l|l|l|}
\hline \multicolumn{3}{|l|}{ Percentage of RDWs who identified the place for delivery while they were pregnant } \\
\hline $\begin{array}{l}\text { Names of } \\
\text { districts } \begin{array}{r}\text { Bumber } \\
\text { of } \\
\text { RDWs surveyed } \\
(\mathrm{n}=500)\end{array}\end{array}$ & $\begin{array}{l}\text { Barabanki } \\
(\mathrm{n}=124)\end{array}$ & $\begin{array}{l}\text { Gonda }(\mathrm{n}=128) \\
(\mathrm{n}=124)\end{array}$ \\
\hline $\begin{array}{l}\text { RDWs who } \\
\text { identified place } \\
\text { of delivery }\end{array}$ & 95 & 96 & 100 \\
\hline $\begin{array}{l}\text { Percentage of RDWs who identified the vehicle for going to hospital in case of emergency while } \\
\text { they were pregnant }\end{array}$ & 95.2 & 93.8 & 100 \\
\hline $\begin{array}{l}\text { RDWs who } \\
\text { arranged vehicle }\end{array}$ & 98.4 & 94 & 100 \\
\hline $\begin{array}{l}\text { Percentage of RDWs who saved money to meet hospital expenses during delivery while they } \\
\text { were pregnant }\end{array}$ & $\begin{array}{l}\text { RDWs who } 98 \\
\text { saved money }\end{array}$
\end{tabular}


This table is on the aspect of birth preparedness. The first aspect of the birth preparedness was the identification of place of delivery during pregnancy. More than $95 \%$ of RDWs identified the place of delivery during pregnancy in all the 4 districts. Next was the identification of the vehicle to be used for emergency transport to hospital. Across all the 4 districts, more than $94 \%$ of RDWs had identified the vehicle. Except for Gonda where $73 \%$ of RDWs said that they had saved money for hospital expenses during delivery, in the rest of the 3 districts more than $94 \%$ of RDWs had saved money for hospital expenses during pregnancy. Earlier discussions on receiving messages on birth preparedness by RDWs showed that most of the RDWs across the 4 districts had received the messages and now it was seen that they had acted after receiving the messages from ASHAs. In Gonda 95\% RDWs had said that they knew about saving money but only $73 \%$ acted. This meant through home visits the ASHAs of Gonda had not discussed the issue of saving money with the family members of RDWs. This activity was best done in an enabling environment at the household where family members cooperated with the RDWs.

Table 2- Natal care of RDWs

\begin{tabular}{|l|l|l|l|l|}
\hline $\begin{array}{l}\text { Number of RDWs } \\
\text { surveyed } \\
(\mathrm{n}=500)\end{array}$ & $\begin{array}{l}\text { Banda } \\
(\mathrm{n}=124)\end{array}$ & $\begin{array}{l}\text { Barabanki } \\
(\mathrm{n}=124)\end{array}$ & $\begin{array}{l}\text { Gonda } \\
(\mathrm{n}=128)\end{array}$ & $\begin{array}{l}\text { Saharanpur } \\
(\mathrm{n}=124)\end{array}$ \\
\hline \multicolumn{3}{|l|}{ Percentage of RDWs replying about who conducted their last delivery } \\
\hline Doctor & 2.4 & 1.6 & 5.5 & 4 \\
\hline ANM/Nurse & 95.2 & 96.8 & 89.1 & 96 \\
\hline Untrained TBA & 2.4 & 0.8 & 3.1 & 0.0 \\
\hline Adult family member & 0.0 & 0.8 & 2.3 & 0.0 \\
\hline
\end{tabular}

The above table was on the natal care of RDWs where the activities surrounding the delivery were discussed. The first part was on the person who conducted the delivery. In all the 4 districts, more than $89 \%$ of the deliveries were conducted by the ANM/nurse. Following nurse was the doctor who conducted about $5 \%$ of deliveries in Gonda and $4 \%$ in Saharanpur. For Banda it was $2.4 \%$ and in Barabanki it was $1.6 \%$. The next category was the untrained TBA who had conducted 3\% deliveries in Gonda, $2.4 \%$ in Banda and about $1 \%$ in Barabanki. About $1 \%$ deliveries in Barabanki were conducted by adult family member and as expected in the most developed district of Saharanpur no deliveries were conducted by adult family members where as it was 2.3 in Gonda. This showed that Gonda had $5.4 \%$ high risk deliveries. In Banda it was $2.4 \%$ and Barabanki followed with $1.6 \%$. In the discussions above, ANM had been the preferred worker and the average contact of ANM with RDWs was 3 during pregnancy which was just next to ASHA. That's why most of the deliveries were also conducted by the ANMs. 


\section{Table 3- Type of last delivery}

\begin{tabular}{|l|l|l|l|l|}
\hline Percentage of RDWs replying about the type of last delivery they had \\
\hline $\begin{array}{l}\text { Names of districts \& } \\
\text { number of RDWs } \\
\text { surveyed }(\mathrm{n}=500)\end{array}$ & Banda $(\mathrm{n}=124)$ & $\begin{array}{l}\text { Barabanki } \\
(\mathrm{n}=124)\end{array}$ & Gonda $(\mathrm{n}=128)$ & $\begin{array}{l}\text { Saharanpur } \\
(\mathrm{n}=124)\end{array}$ \\
\hline Normal & 96 & 96.8 & 94.5 & 94.4 \\
\hline Caesarian & 4 & 3.2 & 5.5 & 5.6 \\
\hline
\end{tabular}

The data on type of deliveries showed that across the 4 districts most of the deliveries of the RDWs were normal deliveries. The percentage of caesarean deliveries in
Saharanpur was 5.6, in Gonda it was 5.5, in Banda it was 4 and in Barabanki it was 3.2 percentages.

Table 4- Decision maker of the place of delivery

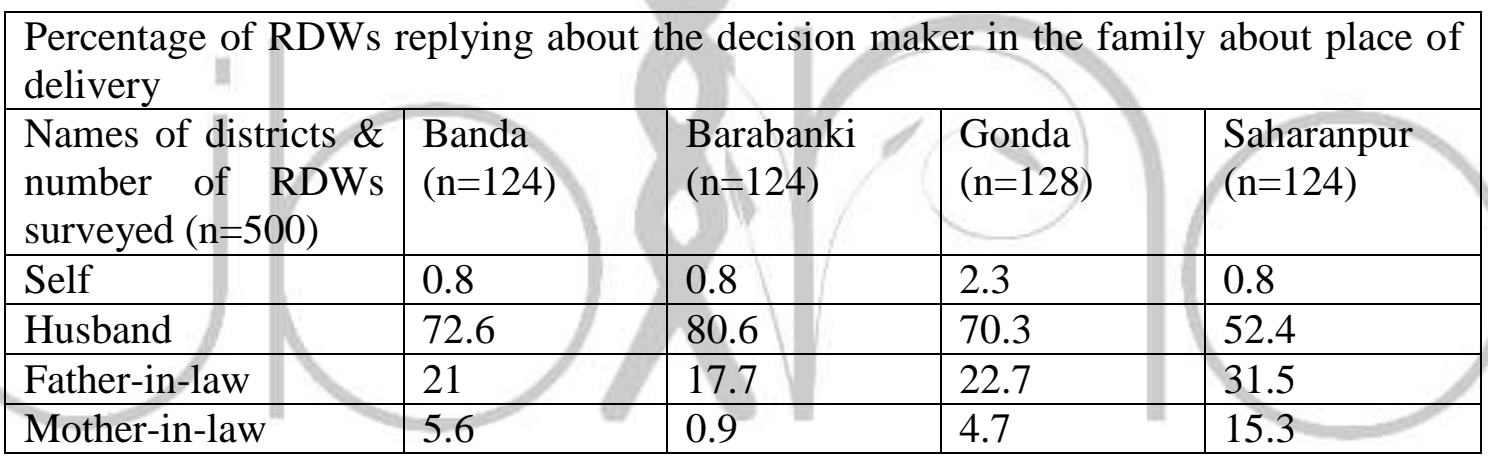

The decision-making process of choosing the place of delivery was mostly taken by the husbands of RDWs. $81 \%$ of RDWs in Barabanki said that husband took the decision, $73 \%$ of RDWs in Banda and $70 \%$ of RDWs in Gonda said husband was the decision maker. Only $52 \%$ of RDWs in Saharanpur said the decision maker was husband. Following was the father-in-law where Saharanpur had 31\%, Gonda with $23 \%$, Banda with $21 \%$ and Barabanki had $18 \%$ of RDWs saying father-in-law as the decision maker. Next decision maker was the mother-in-law where Saharanpur led with $15 \%$, Banda with $6 \%$, Gonda with $5 \%$ and Barabanki with only $1 \%$. Last category was self where RDW took the decision themselves. This category was only $1 \%$ each in Banda, Barabanki and Saharanpur whereas the percentage of RDWs was $2.3 \%$ in Gonda. Here we saw that contrary to the popular belief it was not the mother-in-law but the husbands and the father-in-law who took the decision. 
Table 5- Place of delivery

\begin{tabular}{|l|l|l|l|l|}
\hline Percentage of RDWs replying about the place of delivery & Gonda $(\mathrm{n}=128)$ & $\begin{array}{l}\text { Saharanpur } \\
(\mathrm{n}=124)\end{array}$ \\
\hline $\begin{array}{l}\text { Names of districts \& } \\
\text { number of RDWs } \\
\text { surveyed (n=500) }\end{array}$ & Banda $(\mathrm{n}=124)$ & $\begin{array}{l}\text { Barabanki } \\
(\mathrm{n}=124)\end{array}$ & 4 & 0.0 \\
\hline Own home & 2.4 & 4 & 0.7 & 0.0 \\
\hline Government hospital & 0.0 & 3.3 & 4.7 & 4.8 \\
\hline Government dispensary & 4. & 2.4 & 36.7 & 4.1 \\
\hline PHC/UHP/UFWC rural & 12.1 & 35.5 & 50 & 91.1 \\
\hline $\begin{array}{l}\text { CHC/ } \\
\text { hospital/clinic }\end{array}$ & 54.5 & 0.8 & 3.1 & 0.0 \\
\hline $\begin{array}{l}\text { Private } \\
\text { hospital/clinic/maternity } \\
\text { home }\end{array}$ & 0.0 & & & \\
\hline
\end{tabular}

The data on the place of delivery showed that most of the deliveries were conducted in the $\mathrm{CHCs}$. $91 \%$ deliveries were in $\mathrm{CHC}$ in Saharanpur, $81 \%$ in Banda, 54\% in Gonda and $50 \%$ in Banda. The second place was the PHC which had $37 \%$ in Gonda, 35\% in Barabanki, $12 \%$ in Banda and $4 \%$ in Saharanpur. Government dispensary was the place for $5 \%$ deliveries each in Saharanpur and Gonda, 4\% in Banda and $2 \%$ in Barabanki. Government hospital was the place for $3 \%$ deliveries in Barabanki and $1 \%$ in Gonda. Similarly, 3\% deliveries in Gonda were conducted in private hospital and $1 \%$ in Barabanki was also conducted in private hospital. 5\% RDWs in Gonda and 4\% in Barabanki had home deliveries. 2\% RDWs had home deliveries in Banda and Saharanpur did not have any home deliveries. This showed that most of the RDWs across the 4 districts were conducting their deliveries in public health facilities. Except Banda and Saharanpur districts, the data for home deliveries did not match with the data regarding deliveries conducted by untrained personnel. The deliveries conducted by untrained personnel should have matched with the data on home deliveries as deliveries conducted by untrained personnel are also treated as home deliveries. Table 5 is about reasons for home deliveries. 


\section{Table 6- Reasons for not opting for an institutional delivery}

\begin{tabular}{|c|c|c|c|c|}
\hline \multicolumn{5}{|c|}{$\begin{array}{l}\text { Percentage of RDWs who had home deliveries citing various reasons for not going to } \\
\text { a health facility for delivery }\end{array}$} \\
\hline $\begin{array}{lr}\text { Names } & \text { of } \\
\text { districts } & \& \\
\text { number } & \text { of } \\
\text { RDWs } & \text { surveyed } \\
(n=500) & \end{array}$ & $\begin{array}{l}\text { Banda } \\
(\mathrm{n}=124)\end{array}$ & $\begin{array}{l}\text { Barabanki } \\
(n=124)\end{array}$ & $\begin{array}{l}\text { Gonda } \\
(n=128)\end{array}$ & $\begin{array}{l}\text { Saharanpur } \\
(\mathrm{n}=124)\end{array}$ \\
\hline Facility not open & 0.0 & 0.0 & 1.5 & 0.0 \\
\hline $\begin{array}{l}\text { Do not trust } \\
\text { facility/poor } \\
\text { quality of service }\end{array}$ & 0.8 & 0.0 & 1.5 & 0.0 \\
\hline $\begin{array}{l}\text { No female health } \\
\text { provider at } \\
\text { facility }\end{array}$ & 0.0 & 0.8 & 0.0 & 0.0 \\
\hline $\begin{array}{l}\text { Husband/family } \\
\text { did not allow }\end{array}$ & 1.5 & 3.2 & 1.5 & 0.0 \\
\hline
\end{tabular}

Among the RDWs who had home deliveries, reasons were asked to them for not conducting their delivery at public health facilities. $1.5 \%$ of RDWs in Gonda said that the facility was not kept open. Another $1.5 \%$ of RDWs said that they did not trust the quality and poor quality of service was delivered. 1\% RDW in Barabanki said that there was no female health provider at the facility. 3\% RDWs in Barabanki said they were not allowed by their husbands and the same reason was given by $1.5 \%$ RDWs in Banda and Gonda. Here we found that decision making by husbands at household was the prime reason for not conducting the delivery at health facility there by preferring for a home delivery. So husband's decision making influenced the choice for the place of delivery.

\section{CONCLUSIONS}

The above results showed that the summary of the activities on birth preparedness, place, personnel, type, decision maker and reasons ascribed for not visiting an institution for the recent deliveries vary widely among the four districts. The dissemination process either at home or at an outreach center should also focus on involving all the stake holders while choosing the place of delivery. The foliage of activities on birth preparedness and perinatal care services of RDWs should represent not only three aspects (place, personnel, type) as mentioned in this study but also all the various modalities that comes in to play at the community level. This will help RDWs to address the three delays (place, transport, facility) in maternal death/mortality there by reducing maternal mortality (GOUP, PIP, NHM, 19-20). Data should be collected in large scale surveys on all these parameters of birth preparedness and perinatal care services of RDWs exclusively as they can give significant inputs to improve maternal health. The inclusion of role of health personnel regarding messages/inputs on these activities will help in designing better outreach services regarding maternal 
health. As a result, reduction in MMR \& IMRI.

in UP \& India will follow eventually.

\section{REFERENCES}

Bajpai N, Dholakia R. (2011). Improving the performance of ASHAs in India, working paper No.1, working paper series, globalcentres.columbia.edu/southasia, 2011.

GOI (2005, 2015). Ministry of Health and Family Welfare; Update on the ASHA Programme, April 2005, January 2015.

Government of Uttar Pradesh (2009). Planning Atlas of Uttar Pradesh; Area Planning Division, State Planning Institute, Planning Department.

National Family Health Survey, India, Uttar Pradesh, IIPS, Mumbai, MOHFW, GOI, 201516.

GOl; Ministry of Health and Family Welfare; 2015; Update on the ASHA Programme, January 2015
2. GOUP, Evaluation of ASHA scheme under NRHM in UP, SIFPSA, VIMARSH report, September 2013.

GOUP, Evaluation of CCSP under NRHM in UP, SIFPSA, VIMARSH report, 2013.GOUP, PIP, NHM, 2019.

GOI, planning document, 1974-79, yearly plan 1992.

Singh $\mathbf{R}$, et.al, utilization of maternal health services and its determinants- a cross sectional study among women in rural UP, India, Journal of health, population and nutrition, 38:13, 2019.

SRS bulletin, Vol.52, No.1, RGI, Vital statistics division, GOl, May 2019

SRS, Special bulletin on maternal mortality in India, 2015-17, November, 2019. 